physics. It is, however, equally applicable to college instruction.

The writer presents this discussion with hesitation, for he knows that it is destined to meet with much skepticism. Actual experience has, however, strengthened his conviction that the suggested grading system is decidedly helpful. Indeed, the idea of the grading system here presented is new only in the sense of its successful application to laboratory experiments. If experience has shown a decided value for a grading system in animal husbandry, in oratory, in debate, and in numerous other fields wherein a judgment must be rendered, cannot the ideal be transferred to laboratory instruction? May the instructors of physics who read be willing to test the worth of the suggestion by actual trial!

\title{
ACCELERATION APPARATUS.
}

By Roy C. Andrews;

University of Oregon.

Users of the falling tuning fork apparatus for determining the acceleration due to gravity have experienced difficulty because the trigger release which sets the fork vibrating also gives it a slight downward impulse. Hence the space passed over in the first interval is greater than it should be for a body falling from rest. The following method overcomes this difficulty:

Tie a piece of thread to one prong of the fork, carry it around both pillars, and tie to the other prong. The weight of the fork and its guides is sufficient to spread the prongs slightly, while friction will prevent slipping. To release the fork; simply touch a lighted match to the thread at its middle point. Results by this method and by the old method are given for comparison.

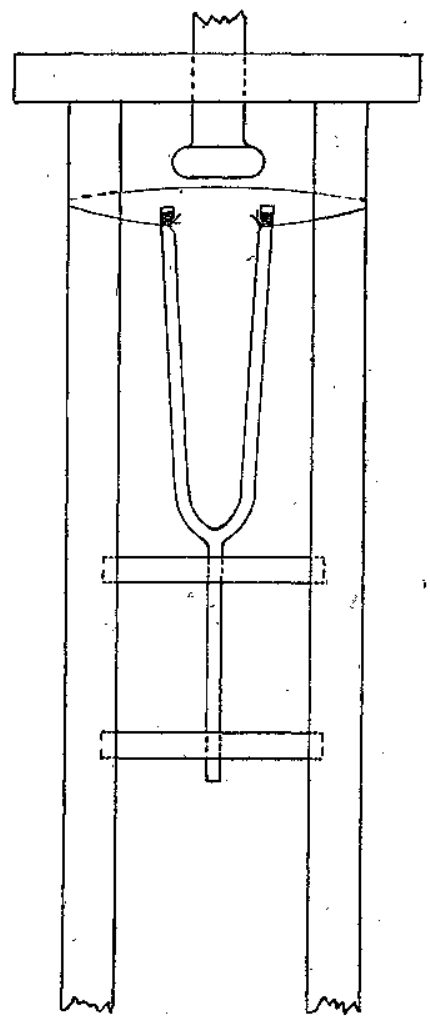


Interval of 10 vibrations

\begin{tabular}{cccc}
\multicolumn{3}{c}{ New Way. } & \\
2 & 3 & 4 & 5 \\
14 & 31.7 & 56.5 & 88.6 \\
10.5 & 17.7 & 24.8 & 32.1 \\
7 & 7.2 & 7.1 & 7.3 \\
$3.9+$ & $8.9+$ & 15.9 & 25 \\
4 & 9 & 16 & 25 \\
& & & \\
$2.9+$ & $4.9+$ & 7 & 9 \\
3 & 5 & 7 & 9
\end{tabular}

Total distance $=s \mathrm{~cm}$. 3.5

Distance in period $=d$. 3.5

Acceleration $=a=7.12$ 7

Comparative distances, $\frac{s}{x / 2 a}=t^{2} \ldots \ldots .98+$ Nearly. 1

Comparative distances, each peri-

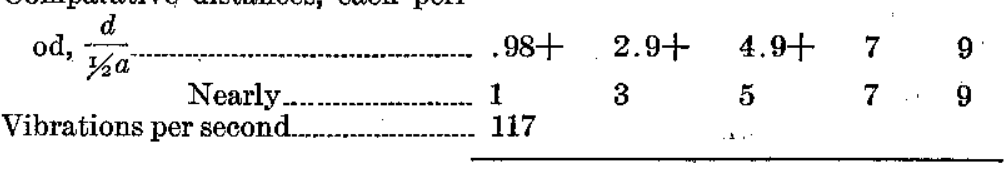

$g=\frac{a}{t^{2}}=\left(\frac{a}{110}\right)^{2}=\frac{7.12 \times(117)^{2}}{100}=975$.

Interval of 10 vibrations.

Total distance $=s \mathrm{~cm}$. 1

Distance in period $=d$ 6

Acceleration $=a=7.12$. 6

Comparative distances, $\frac{s}{\mathrm{I} / 2 a}=t^{2} \ldots \ldots$... $1.5+$ 1 Comparative distances, each period, $\frac{d}{1 / 2 a}$

Vibrations per second

$\frac{7.86 \times(117)^{2}}{100}=1076$

$\frac{7.86 \times(117)^{2}}{100}=1076$

\begin{tabular}{rrrr}
\multicolumn{3}{c}{ Old Way. } & \\
2 & 3 & \multicolumn{1}{c}{5} \\
18.6 & 38.4 & 65.5 & 98.8 \\
12.6 & 19.8 & 27.1 & 33.3 \\
6.6 & 7.2 & 7.3 & 6.2 \\
4.7 & 9.7 & 16.6 & 25.1 \\
& & & \\
3.2 & 5 & 6.9 & 8.4 \\
& & & \\
\hline
\end{tabular}

COCOA.

The plant from which the alkaloid, cocaine, is obtained (Erythroxylon coca) belongs to the Linaceae or flax family and is a native of Peru and Bolivia. It is a shrub six or eight feet high. The leaves have long formed an article of trade among the natives, for which purpose the shrub is extensively cultivated. The leaves are used, either infused in tea or ehewed with a small quantity of powdered lime, which is carried on long journeys in a small gourd. It appears to have been generally used by miners or those making long journeys without the means of securing food, as it lessens the desire for food and produces a feeling of increased energy. An immense amount of fatigue can thus be undertaken combined with a pleasurable effect. When used in moderation it seems to act as a powerf ul stimulant, but in excess it produces a kind of intoxication of the nature of opium and the consequence of its prolonged use is quite as injurious, so, that the habitues among the natives seldom live long. Dr. Spruce, the well-known South American traveler and botan ist, says that the native with a chew of coca in his mouth will often go without food for two or three days without feeling any wish to sleep.-[American Botantist. 